\title{
SILICON COMPATIBLE ACOUSTIC WAVE RESONATORS: DESIGN, FABRICATION AND PERFORMANCE
}

\author{
Aliza Aini Md RAlib AND ANIS NURASHIKIN NORDIN \\ Department of Electrical and Computer Engineering, \\ Faculty of Engineering, International Islamic University Malaysia, \\ P.O. Box 10, 50728, Kuala Lumpur, Malaysia.
}

anisnn@iium.edu.my

\begin{abstract}
Continuous advancement in wireless technology and silicon microfabrication has fueled exciting growth in wireless products. The bulky size of discrete vibrating mechanical devices such as quartz crystals and surface acoustic wave resonators impedes the ultimate miniaturization of single-chip transceivers. Fabrication of acoustic wave resonators on silicon allows complete integration of a resonator with its accompanying circuitry. Integration leads to enhanced performance, better functionality with reduced cost at large volume production. This paper compiles the state-of-the-art technology of silicon compatible acoustic resonators, which can be integrated with interface circuitry. Typical acoustic wave resonators are surface acoustic wave (SAW) and bulk acoustic wave (BAW) resonators. Performance of the resonator is measured in terms of quality factor, resonance frequency and insertion loss. Selection of appropriate piezoelectric material is significant to ensure sufficient electromechanical coupling coefficient is produced to reduce the insertion loss. The insulating passive $\mathrm{SiO}_{2}$ layer acts as a low loss material and aims to increase the quality factor and temperature stability of the design. The integration technique also is influenced by the fabrication process and packaging. Packageless structure using AIN as the additional isolation layer is proposed to protect the SAW device from the environment for high reliability. Advancement in miniaturization technology of silicon compatible acoustic wave resonators to realize a single chip transceiver system is still needed.
\end{abstract}

ABSTRAK: Kemajuan yang berterusan dalam teknologi tanpa wayar dan silikon telah menguatkan pertumbuhan yang menarik dalam produk tanpa wayar. Saiz yang besar bagi peralatan mekanikal bergetar seperti kristal kuarza menghalang pengecilan untuk merealisasikan peranti cip. Silikon serasi gelombang akustik resonator mempunyai potensi yang besar untuk menggantikan unsur-unsur diskret kerana keupayaan untuk mengintegrasikan dengan litar yang disertakan itu. Integrasi ini membawa kepada peningkatan prestasi, fungsi yang lebih baik dengan pengurangan kos pada pengeluaran jumlah yang besar. Oleh itu, Karya ini mengkaji silikon resonator akustik yang serasi, yang bersepadu dengan muka litar untuk membolehkan integrasi yang lengkap. Resonator gelombang akustik yang digunakan adalah gelombang permukaan akustik ( SAW ) dan gelombang akustik pukal ( BAW ) resonator . Kriteria penting untuk menilai prestasi resonator seperti faktor kualiti, frekuensi resonans dan kehilangan sisipan juga digariskan dalam setiap kerja sebelumnya. Pemilihan bahan piezoelektrik yang sesuai adalah penting untuk memastikan pekali gandingan elektromekanik yang mencukupi dihasilkan untuk mengurangkan kehilangan sisipan. Lapisan tambahan pasif $\mathrm{SiO}_{2}$ yang bertindak sebagai bahan rendah sisipan dipercayai meningkatkan faktor kualiti dan kestabilan suhu reka bentuk. Teknik integrasi juga dipengaruhi oleh proses fabrikasi dan pembungkusan. Struktur tanpa pembungkusan menggunakan AlN sebagai lapisan pengasingan tambahan itu dicadangkan untuk melindungi peranti SAW dari persekitaran untuk kebolehpercayaan yang tinggi. Banyak lagi kemajuan perlu dilakukan dalam 
pengecilan silikon serasi resonator gelombang akustik untuk merealisasikan sistem cip transceiver tunggal.

KEYWORDS: RF-MEMS; piezoelectric; resonator; surface acoustic wave (SAW); bulk acoustic wave (BAW); FBAR

\section{INTRODUCTION}

The Internet is evolving from the typical Internet of Data that traditionally shares computers and documents to Internet of Things (IoT) that makes computing truly ubiquitous and able to offer advanced connectivity of devices, system and services [1][2]. To achieve this, varieties of objects have to be able to communicate wirelessly everywhere and to anything. Radio-Frequency identification (RFID) is a key player in the implementation of Internet of Things [3]. To realize ubiquitous wireless connectivity with RFID, a wireless transceiver system that consists of RF integrated circuits needs to be miniaturized [4]. Moore's law predicts an exponential increase in number of transistors and functionality using existing technologies in each year [5]. Although transistors easily meet Moore's law, passive devices are not as easily integrated and miniaturized. The surface acoustic wave (SAW) resonator is one example. The most existing acoustic wave resonators are those based on piezoelectric materials such as quartz $\left(\mathrm{SiO}_{2}\right)$ [6,7], lithium niobate $\left(\mathrm{LiNbO}_{3}\right)$ [8-10], and lithium tantalate $\left(\mathrm{LiTaO}_{3}\right)$ [11,12]. Quartz crystals have been dominating the market because of its accuracy, high quality factor and high temperature stability [13]. However, this resonator imposes some limitations such as incompatibility with silicon and high cost [14]. The potential to integrate the passive devices with circuitry has been offered by Radio Frequency Micro Electromechanical Systems (RF-MEMS) where it can be defined as design and fabrication of MEMS for RF integrated circuits [15]. RF-MEMS is believed to respond to the challenge of Moore's Law by bridging the gap between mature RF circuitry with emerging MEMS devices and crosses the borders between electrical and the mechanical world. RF-MEMS has shown outstanding progression in various applications as shown in Fig. 1 that lead to four important areas such as RF-MEMS switches, RF micromechanical resonators and acoustic wave resonators [16].

RF-MEMS acoustic wave resonators play an important role in replacing bulky and off chip resonators in the telecommunication applications. The innovation of Complementary Metal Oxide Semiconductor (CMOS) as a predominant IC technology allows the RFMEMS resonator to integrate with the other parts circuitry to realize a single chip transceiver system. The resonator has to be fabricated using materials and processes, which do not adversely affect the integrated circuits. Complete integration into a single chip offers 1) low manufacturing cost due to single chip integration at large volume production 2) remarkable performance by reducing the parasitic effects and poor interfacing 3) value-added functionality because it enables multiband configurations, and 4) device sensitivity improvement [14]. Precise resonant frequency, low insertion loss and high quality factors in the range of 10,000 are three crucial requirements for a resonator in the wireless transceiver system [18]. Hence, this paper highlights the previous works on silicon based acoustic wave resonators that have been of great interest for the miniaturization of transceivers. The paper is organized as follows: Section 2 explains the principle of piezoelectricity in acoustic wave resonators; Section 3 and 4 present the design concept of surface acoustic wave and bulk acoustic wave respectively; the state of the art of silicon compatible acoustic wave resonators are discussed and tabulated in Section 5 and 6 respectively. A conclusion is then provided to summarize the findings. 


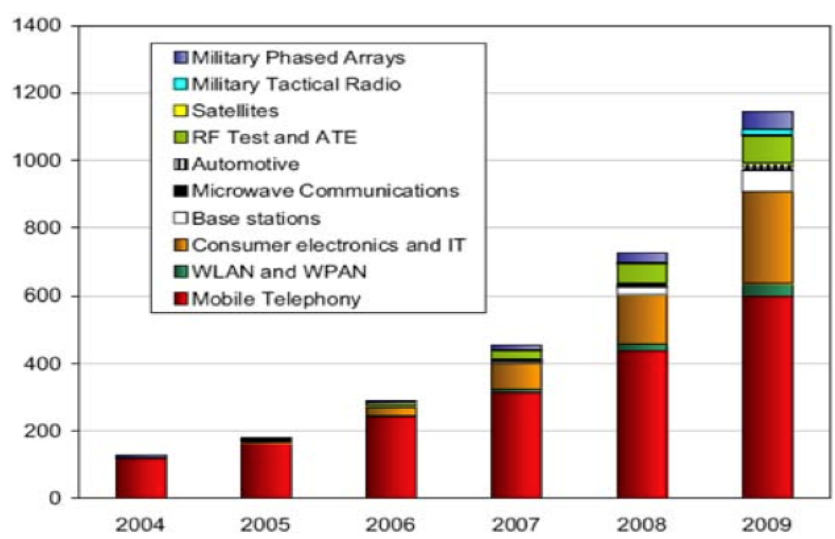

Fig. 1: Evolution of RF-MEMS market [17].

\section{ACOUSTIC WAVE RESONATORS}

An acoustic wave is a type of wave that transfers the energy from the excitation source along a specific medium [19]. The piezoelectric medium is required to allow propagation of acoustic waves, where the acoustic wave phase velocities depend on the material properties [19]. There are two categories of acoustic waves: surface acoustic wave (SAW) and bulk acoustic wave (BAW) resonators. The BAW propagates through the substrates while the SAW propagates along the surface of the substrate. Acoustic resonators experience acoustic wave propagation and vibrate at a resonance frequency. The propagated acoustic waves are trapped in the piezoelectric medium, which behaves as the cavity. Fig. 2 shows the transmission and reflected waves that are trapped in the acoustic cavity in the piezoelectric medium.

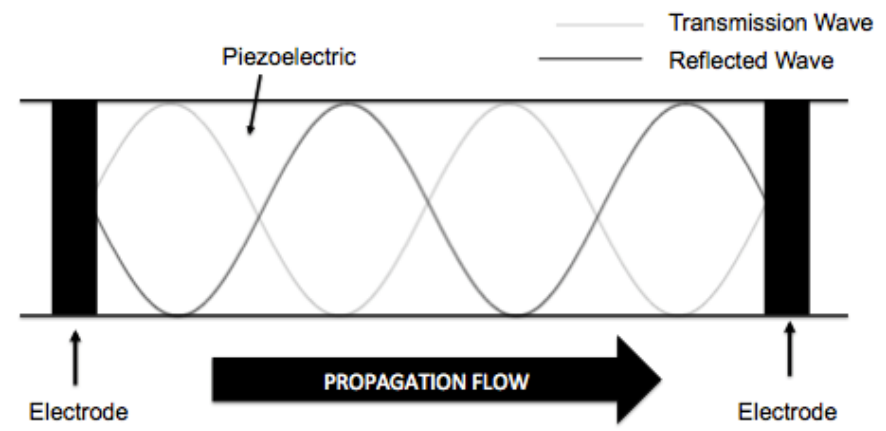

Fig. 2: Propagation of transmission and reflected waves inside resonator [19].

\subsection{Piezoelectricity}

Acoustic wave propagation is based on the piezoelectric theory. The basics of piezoelectric theory are examined in this section. Some crystals become electrically polarized when mechanical strain is applied to the structure. Conversely, when the material is exposed to an electrical field, the materials deform which is called inverse piezoelectric effect [20]. The linear coupling between electricity and elasticity can be described using the constitutive piezoelectric equations in stress charge form as presented in Eqn. (1) and Eqn. (2) where $T$ is the stress matrix, $S$ is the strain matrix, $C$ is the stiffness matrix, $e$ is the piezoelectric constant matrix, $E$ is the electric field, $D$ is the 
electric density displacement matrix and $\varepsilon$ is the permittivity matrix of the piezoelectric material [19].

$$
\begin{aligned}
& T_{6 x 1}=C_{6 x 6}^{E} \cdot S_{6 x 1}-e_{6 x 3} \cdot E_{3 x 1} \\
& D_{3 x 1}=C_{3 x 6} \cdot S_{6 x 1}-\varepsilon_{3 x 3}^{S} \cdot E_{3 x 1}
\end{aligned}
$$

Selection of piezoelectric material is crucial to define the acoustic wave resonator performance. The resonance frequency is determined by acoustic phase velocity, which is strongly influenced by the selection of the substrate material [21]. Piezoelectric materials can be divided into three types: polycrystalline ceramics $\left(\mathrm{LiNbO}_{3}\right.$ and $\left.\mathrm{LiTaO}_{3}\right)$, piezoelectric single crystal materials (quartz), and piezoelectric thin films ( $\mathrm{ZnO}$ and $\mathrm{AlN}$ ) [22]. The uniformity of ferroelectric materials such as $\mathrm{LiNbO}_{3}$ and $\mathrm{LiTaO}_{3}$ is crucial because these materials need polarization and optimal orientation at specified Euler angles [8]. Table 1 shows the material properties of common piezoelectric materials [19]. To meet the demand of high frequency applications and miniaturization, the development of thin film piezoelectric materials is rapidly accelerating. Piezoelectric thin film offers high sensitivity with large dynamic ranges, low power requirements and compatible with electronic circuits, which lead to single chip devices [19].

Table 1: Piezoelectric material properties for SAW and BAW resonators.

\begin{tabular}{cccccc}
\hline Material & Types & $\begin{array}{c}\text { Dielectric } \\
\text { Constant }\end{array}$ & $\begin{array}{c}\text { Density } \\
\left(\mathbf{k g} / \mathbf{m}^{\mathbf{3}}\right)\end{array}$ & $\begin{array}{c}\text { Acoustic } \\
\text { Velocity (m/s) }\end{array}$ & $\begin{array}{c}\text { Acoustic } \\
\text { coupling }\end{array}$ \\
\hline LiNbO $_{3}$ & Ceramics & 29 & 4640 & 7320 & 0.17 \\
$\mathbf{L i T a O}_{3}$ & Ceramics & 43 & 7450 & 6160 & 0.19 \\
$\mathbf{Z n O}$ & Thin film & 8.8 & 5680 & 6330 & 0.17 \\
AlN & Thin film & 8.5 & 3270 & 10,400 & 0.28 \\
\hline
\end{tabular}

\section{SURFACE ACOUSTIC WAVE (SAW) RESONATOR}

\subsection{Design Concept}

Surface acoustic wave resonator is a resonant cavity where it consists of an interdigitated transducer (IDT) and reflectors deposited on top of the piezoelectric substrate as shown in Fig. 3.

The operating principle of the SAW device is based on the piezoelectric effect. Acoustic waves are generated by the IDTs on the surface of the substrate when a microwave input signal is applied at the input IDT. The acoustic waves then propagate along the surface of the substrate. The SAW generates an electric field which is translated back to the electrical signal at the output of the IDT [23]. The function of the reflector is to reflect the acoustic waves so it will be trapped inside the cavity to reduce the loss [24]. The frequency of the SAW devices, $\left(f_{r}\right)$ strongly depends on the velocity of the acoustic wave $(v)$ and the wavelength $(\lambda)$ as shown in Eqn. (3). The frequency of operation of the SAW resonator is determined by the periodic spacing between the IDTs as indicated in Fig. 3. The IDTs are fabricated using photolithography techniques. However, the 
resolution in the standard photolithography technique limits the maximum frequency of operation of the resonator.

$$
v=f_{r} \lambda
$$

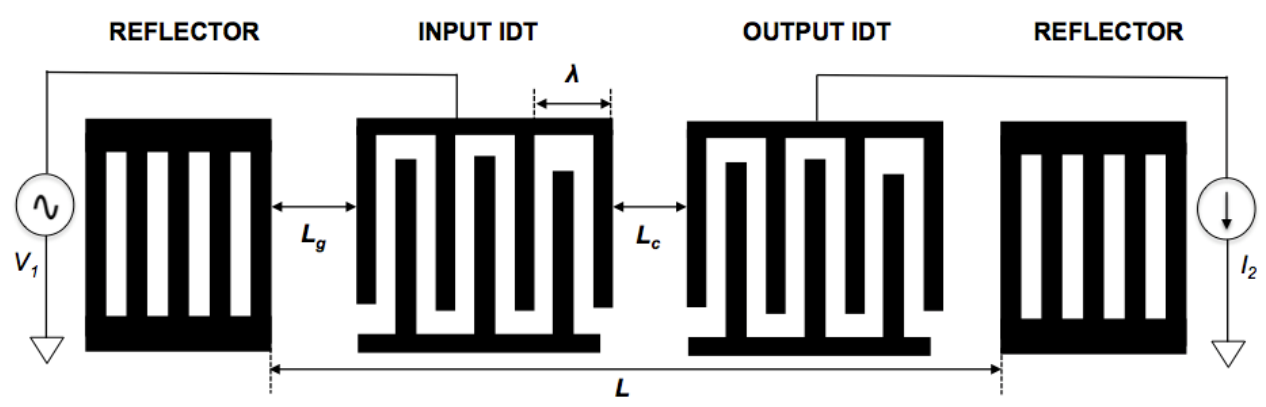

Fig. 3: Top view of 2-port SAW resonator with reflectors on both sides.

\subsection{Equivalent Circuit Modeling}

Figure 4 shows the generic equivalent circuit model for a SAW resonator. The model is categorized into two components: acoustic and parasitic components. $R_{x}, L_{x}$ and $C_{x}$ electric circuit elements describe the acoustic component while $C_{T}$ shows the parasitic component due to parasitic capacitance between the layers in the resonator [24]. An equivalent circuit was developed by Datta [25] to calculate acoustic admittance. As shown in Fig. 3, an input voltage, $V$ is applied at the input IDT. The acoustic wave is generated in the piezoelectric layer and induces the current, $I$ at the output IDT. The ratio of input voltage and output current is termed as the admittance which consists of radiation conductance $\left(G_{1}\right)$ and radiation susceptance $\left(B_{1}\right)$ as shown in Eqn. (4) and Eqn. (5). In the latter equation, $k^{2}$ is the coupling coefficient and $N_{T}$ is the number of transducers.

$$
\begin{aligned}
& Y_{1}(f)=G_{1}(f)+j B_{1}(f) \\
& G_{12}(f)=8 \kappa^{2} N_{T}^{2} f_{r} C_{T}
\end{aligned}
$$

To add the effect of reflectors for the SAW resonator, the small reflectivity, $r$ is calculated based on Eqn. (6). The variable is as shown: $\Delta=\eta \pi$, the metallization ratio $\eta=$ 0.5 and the Legendre polynomials are $P_{0.5}(\cos \Delta)=1.5061$ and $P-0.5(\cos \Delta)=1.3280$ [26]. Total reflection, $\Gamma$ is achieved by determining the array of reflectivity as shown in Eqn. (7). The admittance is modified to add the effect of reflectors based on the array of reflectivity as shown in Eqn. (8) and Eqn. (9) where $L_{g}$ is the distance between IDT and reflectors and $L_{p}$ is the effective penetration length.

$$
\begin{aligned}
& r=j\left|\frac{1}{2} \kappa^{2}\right| \frac{\pi}{2}\left((-\cos \Delta)+\frac{P_{0.5}(\cos \Delta)}{P_{-0.5}(\cos \Delta)}\right) \\
& |\Gamma| \cong \tanh N|r| \\
& G_{s}\left(f_{r}\right)=G_{12}(f) \frac{1+2 \Gamma \cos (4 \pi \delta / \lambda)+\Gamma^{2}}{1-\Gamma^{2}}
\end{aligned}
$$




$$
\delta=L g+L p+\left(N_{t} \frac{\lambda}{2}\right)
$$

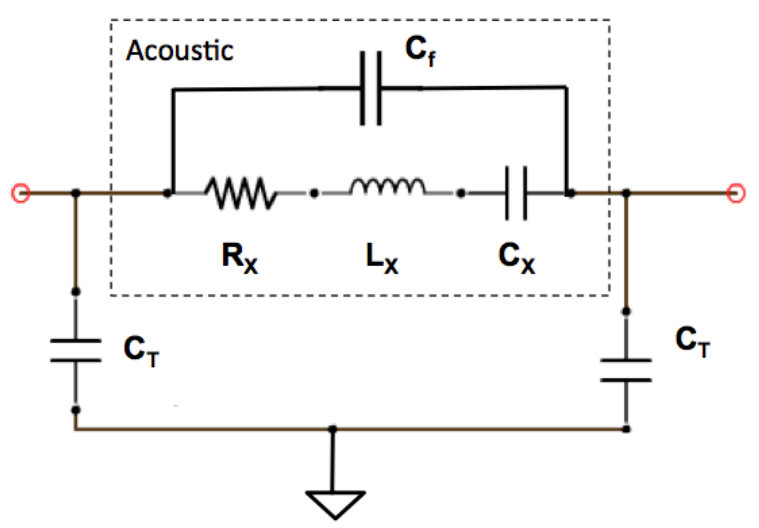

Fig. 4: A SAW resonator is implemented to design oscillator using feedback element and the equivalent circuit modeling.

\section{BULK ACOUSTIC WAVE}

\subsection{Design Concept}

Bulk acoustic wave (BAW) resonators have gained explosive interest in the communication market and research because of its excellent performance in reaching up to $10 \mathrm{GHz}$ in resonance frequency [19], [27]. The BAW resonator consists of a stacked element structure: metal top electrode/piezoelectric, and material/metal bottom electrode where the acoustic wave is restricted between the IDT as shown in Fig. 5. The stacked element is fabricated on a supporting substrate (typically silicon). A voltage is applied to the resonator electrodes and induces mechanical strain of the acoustic layer. BAW propagates through the bulk of a piezoelectric material. The acoustic waves produce an electric field which can be read out at the electrodes [19].

The resonance frequency of a BAW resonator is mainly determined by the thickness of the acoustic layer as shown in Eqn. (10) where $\theta, v, f_{r b}$ and $t$ is the phase, velocity, resonance frequency for the BAW resonator, and thickness of the thin film respectively [19].

$$
\begin{aligned}
& \theta=\frac{2 \pi f_{r b} t}{v} \\
& f_{r b}=\frac{v}{2 t}
\end{aligned}
$$

At resonance frequency, the acoustic phase is $\pi$ and therefore the fundamental resonance mode leads to Eqn. (11). For the first resonance mode, the thickness of the piezoelectric thin film is equal to the half wavelength of the BAW [19]. 


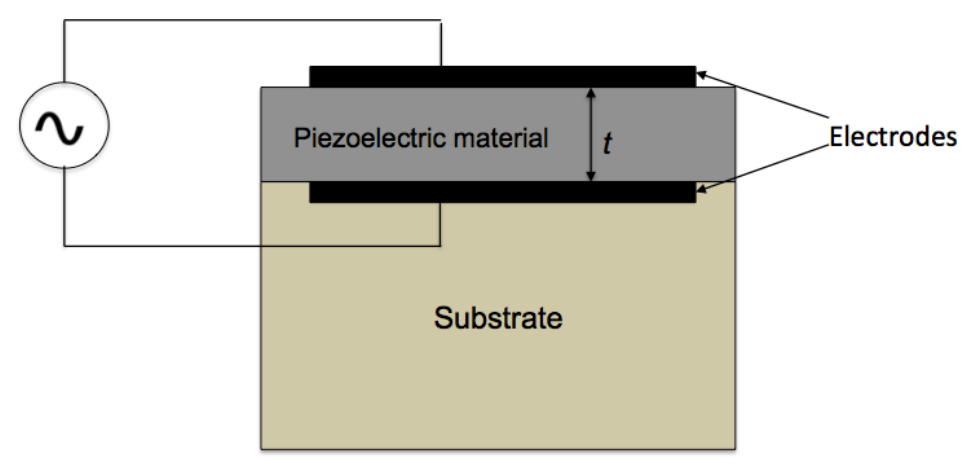

Fig. 5: Bulk acoustic wave resonator.

\subsection{Equivalent Circuit Modeling Based on Modified BVD Model for BAW Resonator}

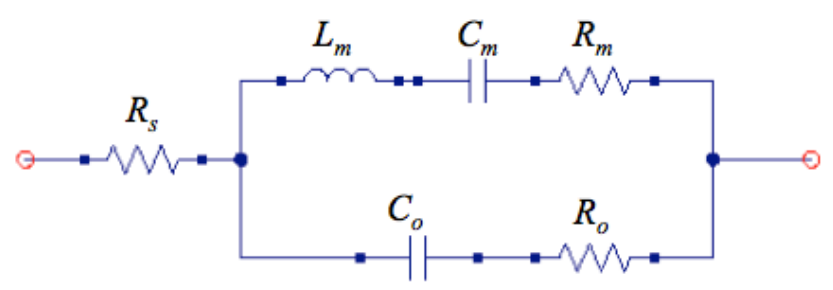

Fig. 6: Modified BVD model for BAW resonator.

As depicted in Fig. 6, The BAW resonator can be modelled by the modified Butterworth Van Dick (BVD) model. The mechanical resonance behaviour is presented by motional resistance $\left(R_{m}\right)$, motional capacitance $\left(C_{m}\right)$ and motional inductance $\left(L_{m}\right)$. Static capacitance $\left(C_{o}\right)$ occurs because of the capacitance sandwiched between the top and bottom electrodes. In order to match the model closely with BAW resonators, two additional loss resistors: $R_{S}$ (resistance of routing pads and electrodes) and $R_{o}$ (parasitic resistance in the Si substrate) are proposed as illustrated in Fig. 6 [28] . Series and parallel resonance frequencies are obtained as shown in Eqn. (12) and Eqn. (13) respectively. The equivalent impedance is presented in Eqn. (14). The admittance can be expressed in Eqn. (15).

$$
\begin{aligned}
& f_{s}=\frac{\omega_{s}}{2 \pi}=\frac{1}{2 \pi} \sqrt{\frac{1}{L_{m} C_{m}}} \\
& f_{p}=f_{s}\left(1+\frac{C_{m}}{C_{o}}\right)=\frac{1}{2 \pi} \sqrt{\frac{1}{L_{m} C_{m}}\left(1+\frac{C_{m}}{C_{o}}\right)} \\
& Z(\omega)=R_{s}+\frac{\left(R_{o}+\frac{1}{j \omega C_{o}}\right)\left(R_{m}+\frac{1}{j \omega C_{m}}+j \omega L_{m}\right)}{R_{o}+\frac{1}{j \omega C_{o}}+R_{m}+\frac{1}{j \omega C_{m}}+j \omega L_{m}}
\end{aligned}
$$




$$
Y(\omega)=\frac{1}{Z(\omega)}
$$

To define the performance of a BAW resonator, the quality factor, Q is calculated as shown in Eqn. (16) and Eqn. (17). For simplification of an RLC circuit, the quality factor can be calculated as the ratio of the series resonance frequency to the two-sided $3 \mathrm{~dB}$ bandwidth as shown in Eqn. (18). Figure 7 illustrates the typical admittance and phase to evaluate the performance of the SAW and BAW resonator [29].

$$
\begin{aligned}
& Q_{s}=\frac{1}{\omega_{s}\left(R_{m}+R_{s}\right) C_{m}} \\
& Q_{p}=\frac{1}{\omega_{p}\left(R_{m}+R_{o}\right) C_{m}} \\
& Q=\frac{f_{s}}{\Delta f_{3 d B}}
\end{aligned}
$$

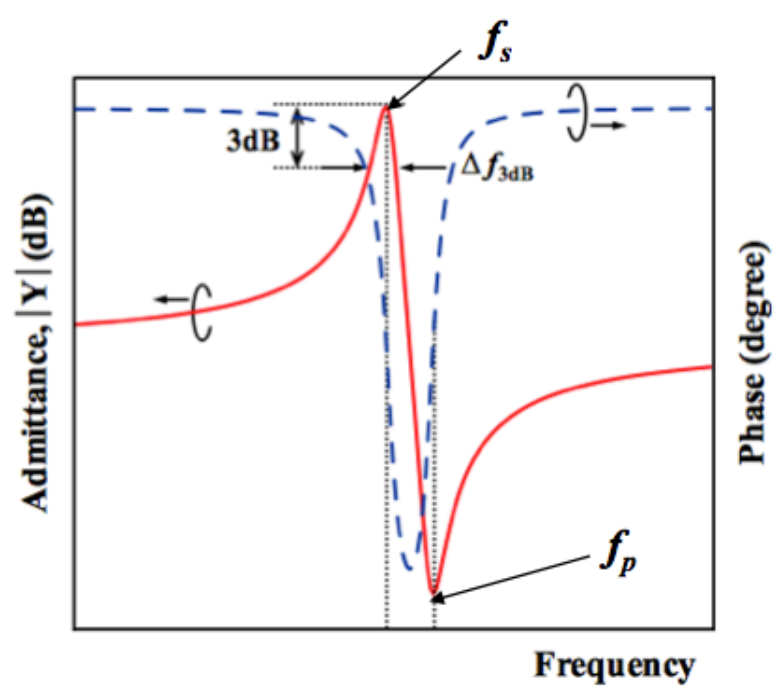

Fig. 7: Admittance and phase of SAW and BAW resonator [29].

There are two types of BAW devices: thin film bulk acoustic wave resonator (FBAR) and solidly mounted resonators (SMR). The difference between these two BAW devices is the method of acoustical isolation to increase the quality factor either by exhibiting the air gap or implementing and array of reflecting materials known as the Bragg's reflector as shown in Fig. 8 [19]. To acquire high quality factors for a FBAR device, bulk micromachining process through dry or wet etching are needed to create the air gap underneath the resonator as illustrated in Fig. 8(a) [19]. A stack of acoustically mismatched layers which act as the Bragg reflector are fabricated under the resonator for SMR resonator as shown in Fig. 8(b). 


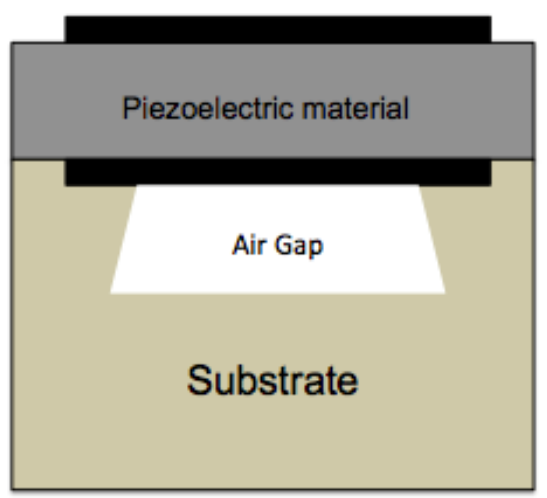

(a)

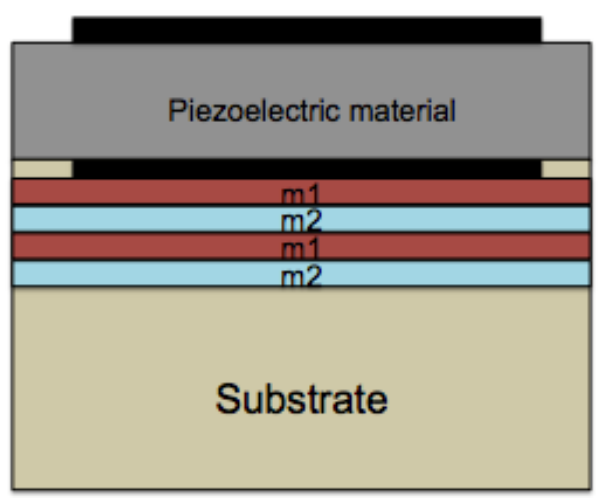

(b)

Fig. 8: Stacked structure of BAW resonator (a) Thin film BAW (FBAR) that consists of air gap (b) Solidly mounted resonator (SMR) that consists of Bragg reflector.

\section{RECENT TECHNIQUES ON SILICON COMPATIBLE SAW RESONATORS AND FILTERS}

Acoustic wave resonators for surface acoustic wave (SAW) technology have rapidly developed and can reache up to GHz frequency [12]. The integration of SAW devices with accompanying circuitry, as a single chip is essential to reduce insertion loss, simplify the packaging, and reduce the device size and area. Recent work by researchers to realize on chip SAW devices are described below.

\subsection{GHz SAW Resonators Fabricated Using E-beam Lithography Techniques}

As specified in Eqn. (3), the resonance frequency is related to $\lambda$ or the periodic spacing of the transducers. This is determined by the lithography process. For example, $0.35 \mu \mathrm{m}$ CMOS technology is able to design SAW resonators with maximum resonance frequency of $1.125 \mathrm{GHz}$ and has minimum periodic spacing of $3.2 \mu \mathrm{m}$. Due to conventional photolithography limitation, the resonance frequency is restricted according to CMOS technology for existing SAW resonators [30]. Hence, to meet the demand for future generation of telecommunication systems, a two port SAW resonator operating at $5.035 \mathrm{GHz}$ was designed [30]. Nanolithographical process was proposed to pattern the IDT with a periodic spacing of $\lambda=1.2 \mu \mathrm{m}$. The $300 \mathrm{~nm}$ widths of IDTs were manufactured using e-beam lithography techniques on high resistivity (100) silicon substrates. The resonator consists of 40 fingers on top of a $1.4 \mu \mathrm{m}$ AlN thin film. AlN was chosen as the piezoelectric layer because it has high acoustic velocity, good thermal stability and compatible with integrated circuits [30]. Figure 9 illustrates the SEM images of an AlN SAW structure. The S parameter measurement result shows the resonance peak at 5.035 $\mathrm{GHz}$ and $65 \mathrm{~dB}$ insertion loss. The acoustic velocity and electromechanical coupling coefficient are $600 \mathrm{~m} / \mathrm{s}$ and $0.53 \%$ respectively. A highlight of this work is the advancement of e-beam lithography techniques that are able to address the limitations faced by conventional lithography techniques. Hence a device with a higher resonance frequency of up to $5 \mathrm{GHz}$ has been successfully designed. The device also has potential to be integrated with current active devices. However, improvement of the device is still needed to reduce the insertion loss. 


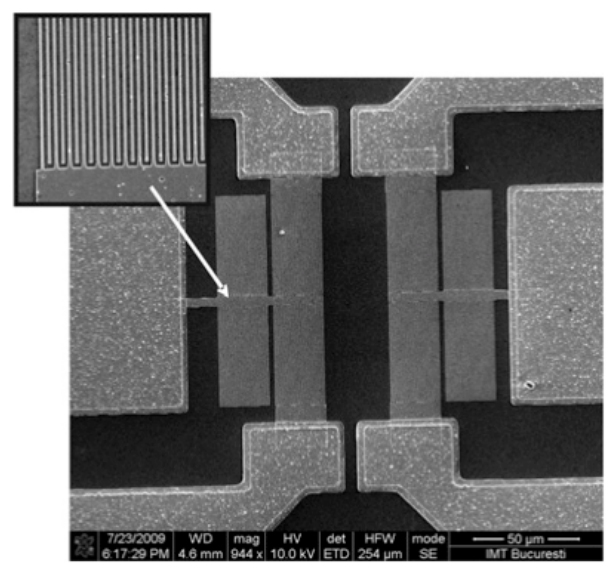

Fig. 9: SEM images of AlN SAW structure [30].

\subsection{Accurate FEA-BIM Modeling for GHz Frequency $\mathrm{ZnO/Si} \mathrm{SAW} \mathrm{Device}$}

This work proposes intensive modeling based on the boundary integral method (BIM) coupled with finite element analysis (FEA) to predict the possibility of excitation for highfrequency modes. Resonance peaks that show different wave modes and associated harmonics were theoretically identified, measured and compared in the range of $600 \mathrm{MHz}$ to $3540 \mathrm{MHz}$. The SAW device is based on a $\mathrm{ZnO} / \mathrm{Si}$ structure that was fabricated using conventional photolithography [31]. ZnO was chosen because of its strength in the piezoelectric coupling coefficient compared to AlN. 50 IDT finger pairs have been patterned using conventional photolithography and wet etching. The measured resonance frequencies at the third and fifth harmonic of the structure are $2.5 \mathrm{GHz}$ and $3.5 \mathrm{GHz}$ respectively. This work proves that conventional lithography is able to achieve $\mathrm{GHz}$ range resonance frequency by exploiting the $3^{\text {rd }}$ harmonics of the guided modes [31]. The modeling also successfully characterizes accurate analysis for harmonic modes. The good agreement with theoretical formulation provides reliable data to improve the design. As shown in Fig. 10 (a) and (b), good agreement is shown between the fitted model and experimental result for admittance and temperature coefficient at $2.4 \mathrm{GHz}$ resonance frequency respectively. Thus, the model provides a reliable set of parameters to improve the performance of the SAW devices.

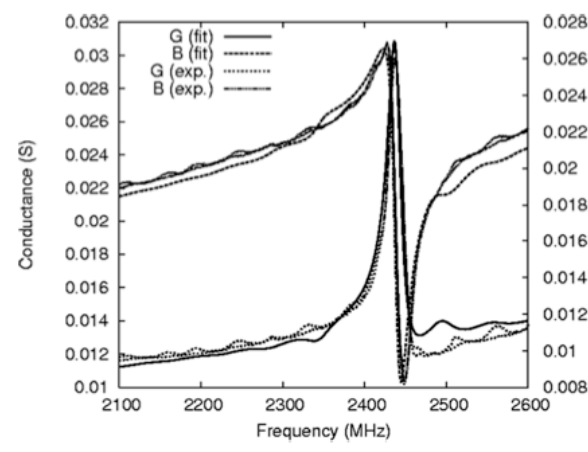

(a)

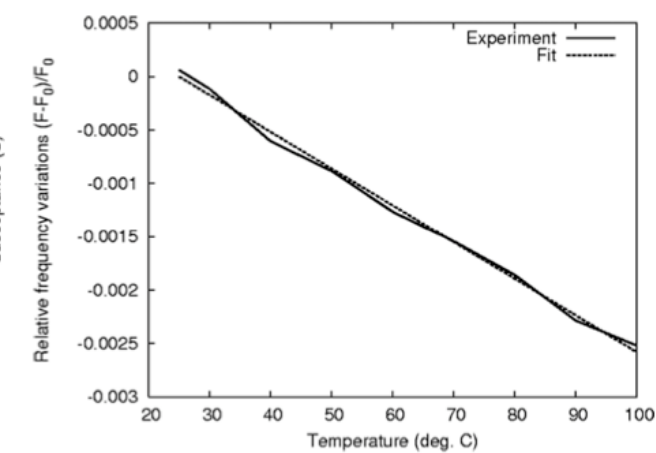

(b)

Fig. 10: (a) Comparison performance between P-matrix model and the experimental measurement of SAW resonator at $2.4 \mathrm{GHz}$ (b)Temperature coefficient of frequency that shows TCF value of $-34.4 \mathrm{ppm} / \mathrm{K}$ [31]. 


\subsection{Packageless AIN/ZnO/Si Structure for SAW Devices Applications}

To protect SAW devices from the environment, there are a number of techniques for SAW packaging such as vacuum encapsulation and TO-8 packages. However, these packaging techniques limit the miniaturization. Two essential theories for packageless structures were reported in [32]: 1) Isolated layer acoustic wave (ILAW) that form Bragg reflection based on high and low acoustic impedance layer 2) wave-guiding layer acoustic wave (WLAW). A packageless structure for SAW devices based on AlN/interdigital transducers/ZnO/Si structure is illustrated in Fig. 11 [32]. AlN act as protective layer because of its high hardness, high stability and two times larger SAW velocity compared to $\mathrm{ZnO}$. To prove the significant relationship between additions of AlN isolation layer on $\mathrm{ZnO}$ layers, $\mathrm{ZnO} / \mathrm{Si}$ design was first simulated. The result shows that the $0^{\text {th }}$ and $1^{\text {st }}$ mode exhibits better coupling coefficients compared to the $2^{\text {nd }}$ mode. Increment of the $\mathrm{ZnO}$ layer thickness for the $0^{\text {th }}$ mode directly improves the coupling coefficient up to $2.3 \%$ [32]. The design of $\mathrm{AlN} / \mathrm{ZnO} / \mathrm{Si}$ was also simulated to determine the relationship between required AlN and $\mathrm{ZnO}$ thickness for efficient package-less structure. SAW performance at the $1^{\text {st }}$ mode for $\mathrm{AlN} / \mathrm{ZnO} / \mathrm{Si}$ structure degrades with the increases of AlN film thickness and stabilized at $k_{2}=1 \%$. The stabilization of coupling coefficient shows the isolation of the wave at the required AlN thickness. There is a trade-off between normalized $\mathrm{ZnO}$ and AlN isolation layer thickness to design efficient performance of a package-less structure. Thus, there is high potential for the AlN/ZnO/Si device to confine the wave in order to create a package-less structure that is suitable for liquid sensing application.

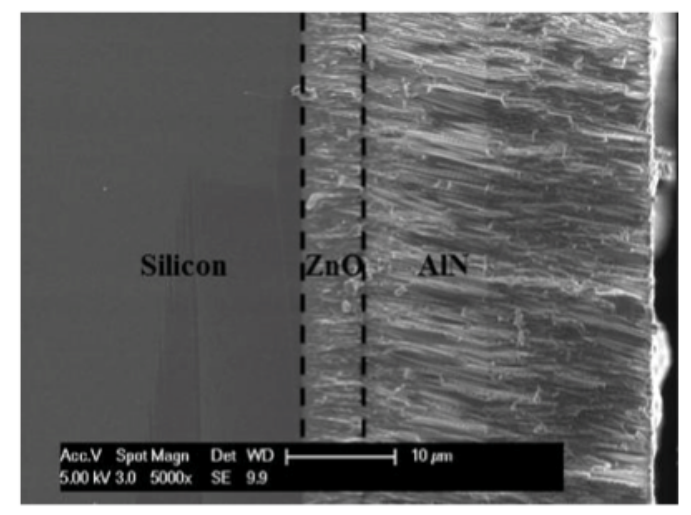

Fig. 11: Cross-sectional SEM image of the AlN/ZnO/Si structure [32].

\subsection{Integrated CMOS SAW Resonator}

A two port CMOS SAW resonator for monolithic integration of SAW-CMOS was demonstrated in this work using $0.6 \mu \mathrm{m}$ American Microsystems Incorporated (AMI) CMOS three metal two poly CMOS process [24]. Metal 1 and Metal 2 of the CMOS metal layers were designed to realize IDTs, reflectors and ground shield as shown in Fig. 12. Reflectors create resonance within the cavity to reduce the loss of the acoustic waves. To realize $\mathrm{GHz} \mathrm{SAW}$ resonator, zinc oxide $(\mathrm{ZnO})$ was chosen as the piezoelectric material due to its excellent bonding to a silicon substrate, and having high piezoelectric coupling. Post CMOS process that involves reactive ion etching, zinc oxide deposition and wet etching were implemented. Three different resonators were designed with different operating frequencies of $1.02 \mathrm{GHz}, 941 \mathrm{MHz}$, and $605 \mathrm{MHz}$. The highlight of this work is the successful fabrication of a CMOS SAW resonator which eliminates the separate deposition steps for resonator fingers. The fabricated CMOS SAW resonators exhibited insertion losses between $35-45 \mathrm{~dB}$ with quality factors in the range of 30 to 254 [24]. To 
reduce the insertion losses, the reflector's height is increased by employing metal layer M3. A stack of reflectors in CMOS and external matching circuits were implemented. However, further improvements are needed to increase the $\mathrm{Q}$ factor to meet the requirements of commercial communication devices that have quality factor in the 10,000 range [18].

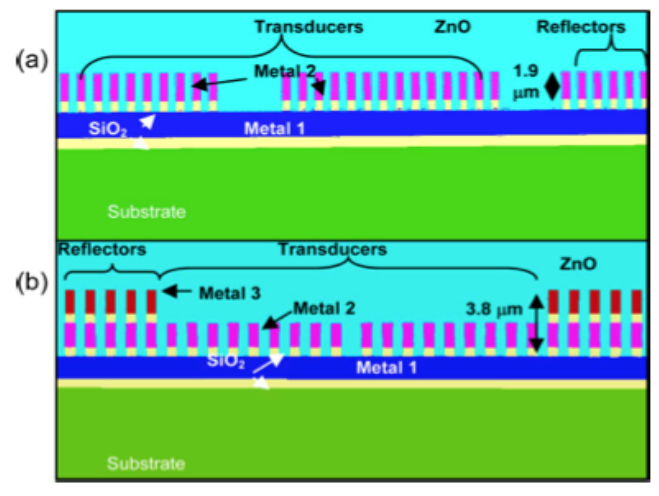

Fig. 12: (a) Cross section of CMOS SAW resonator implementing Metal 1 and Metal 2 CMOS metal layers as IDT, reflector and ground shield. (b) Improved implementation of CMOS SAW resonator by utilizing metal 3 as extra layer of reflectors [24].

\subsection{The Role of Si Substrate Resistivity for CMOS Integrated AIN Based SAW Filter}

A SAW delay lines device that consists of $\mathrm{AlN} / \mathrm{SiO}_{2} / \mathrm{Si}(100)$ layers was designed for CMOS compatible SAW filters [33]. The wavelength of the IDT is $1.68 \mu \mathrm{m}$. An AlN piezoelectric layer was deposited by reactive pulse DC sputtering. To get access to metal GSG pads, a reactive ion etching step was done to partially remove the AIN layer. This work demonstrated the relationship between the resistivity of a Si substrate and the out of band insertion band loss. As the substrate resistivity decreases, out of band insertion loss decreases due to the electrical feed-through between the IDT and the substrate becoming more conductive [34]. The small out of band insertion loss will degrade the SAW performance. The resonator exhibits resonance peak at a fundamental mode of about $2.4-$ $2.5 \mathrm{GHz}$ with acoustic velocity of $4200 \mathrm{~m} / \mathrm{s}$. Experimental measurement shows higher $\mathrm{Si}$ substrate resistivity $(4000 \Omega \mathrm{cm})$ leads the improvement of out of band insertion loss of 60 $\mathrm{dB}$ as shown in Fig. 13. Therefore, high Si substrate resistivity is crucial to contribute high out of band insertion loss due to reduced capacitive coupling to the substrate. Consequently, SAW performance is improved by using high Si substrate resistivity [33], [34].

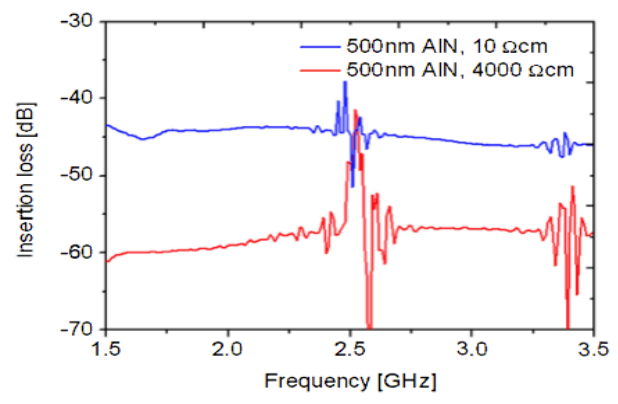

Fig. 13: S21 parameter for $500 \mathrm{~nm}$ AlN SAW filters for two different substrate resistance [33]. 


\section{RECENT TECHNIQUES ON SILICON COMPATIBLE BAW RESONATORS AND FILTERS}

Bulk acoustic wave (BAW) devices have rapidly emerged to address high frequency applications and competitive to SAW [35]. The heart of BAW devices is excellent properties of piezoelectric thin film such as AlN, ZnO and PZT [36]. The deposition technique and thickness of piezoelectric material plays crucial role to determine the performance of BAW resonator. Several previous works have been discussed comprehensively and a complete comparison table will also be attached at the end of the discussion.

\subsection{Alternating Layers of Tungsten/SiO $\mathrm{Si}_{2}$ as Acoustic Reflector for FBAR-CMOS Oscillator}

To have a high quality factor and allow minimal movement, two methods were proposed for FBAR structure: suspended piezoelectric membranes by undercut etching and acoustic reflectors [37]. The highlight of this work is the design of solid mounted resonators that derive isolation from acoustic reflectors using alternating layers of tungsten/ $/ \mathrm{SiO}_{2}$. This is to ensure that most of the mechanical energy is reflected back into the resonator. A monolithic solidly mounted FBAR oscillator 6 x 4 array on $0.18 \mu \mathrm{m}$ CMOS active substrate was developed [37]. The micrometer size of FBAR can interface directly with active an CMOS substrate to produce a low cost and robust sensor for biological and chemical detection. As shown in Fig. 14, the device consists of a $\mathrm{ZnO}$ piezoelectric layer sandwiched between electrodes. Pierce oscillator topology was chosen using $0.18 \mu \mathrm{m}$ RF CMOS technology. Post CMOS fabrication was done to fabricate the FBAR structure on top of the CMOS device. The final die size is $3 \mathrm{~mm} \times 5 \mathrm{~mm}$. The fabricated FBAR CMOS oscillator depicts resonant peak at $905 \mathrm{MHz}(\mathrm{Q}=113)$ and second harmonic modes at $2.18 \mathrm{GHz}(\mathrm{Q}=129)$ [37]. Further tuning of the acoustic reflector layer thickness is possible to enhance the quality factor. The output spectrum shows resonance at $864.5 \mathrm{MHz}$ with phase noise of $-83 \mathrm{dBc} / \mathrm{Hz}$ (offset of $10 \mathrm{kHz}$ ) and $-104 \mathrm{dBc} / \mathrm{Hz}$ (offset of $100 \mathrm{kHz}$ ) [37]. The advantages of the design are its small footprint area, robustness, direct connection with interface circuits. Its fabrication also skips the stage for chemical undercut etching for mechanical isolation.

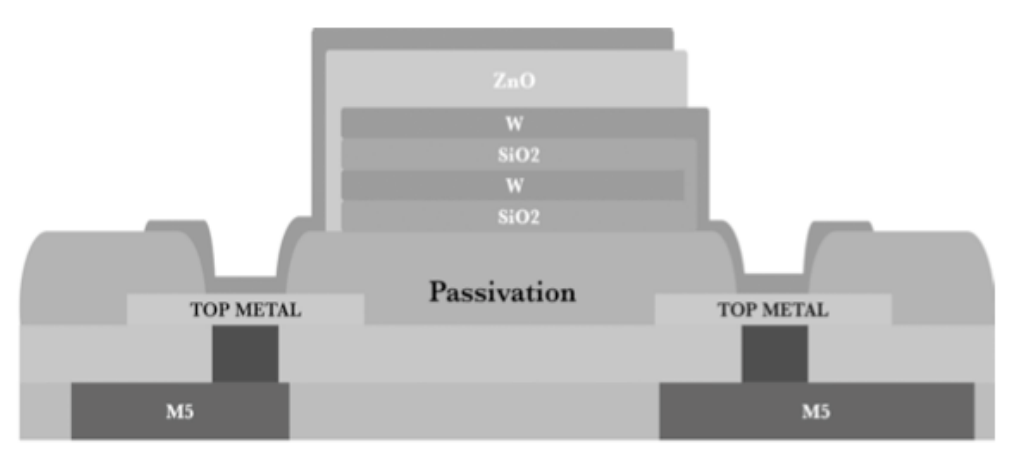

Fig. 14:Cross section of FBAR CMOS oscillator [37].

\section{2 $\mathrm{Pb}\left(\mathrm{Zr}_{0.53} \mathrm{Ti}_{0.47}\right) \mathrm{O}_{3}$ in Thin Film Bulk Acoustic Resonators Fabricated using Sol-gel Technique}

A thin film BAW resonator (TFBAR) with platinum electrodes on $\mathrm{Si}$ wafers was reported [38]. For the first time to our knowledge, $\{111\}$-textured $\mathrm{Pb}\left(\mathrm{Zr}_{0.53} \mathrm{Ti}_{0.47}\right) \mathrm{O}_{3} \mathrm{PZT}$ 
material is used for a BAW resonator and was deposited via a sol-gel technique [38]. Although PZT has a high coupling coefficient compared to AlN and $\mathrm{ZnO}$, the high acoustical attenuation of the material gives very low quality factor. The cross section of TFBAR with double resonator membrane structure is shown in Fig. 15. This work discussed the characterization of PZT materials properties that is dedicated for a TFBAR resonator. The Xray diffraction image shows that the PZT thin film lies in a pure perovskite structure with $\{111\}$ preferred orientation which leads to good crystallinity [38]. AFM images depicts that the surface roughness does not affect the resonance peak. An optimal applied bias voltage of $-15 \mathrm{kV} / \mathrm{cm}$ was observed to get the optimum dielectric and piezoelectric constants as a function of electric field. The results show optimum performance of the resonator at a bias voltage of $-15 \mathrm{kV} / \mathrm{cm}$ with a coupling constant of $10 \%$ and $\mathrm{Q}=50$ [38]. Although the coupling constant is high, the PZT material needs additional steps of polarization at a different orientation to ensure optimum electroacoustic interaction for BAW performance.

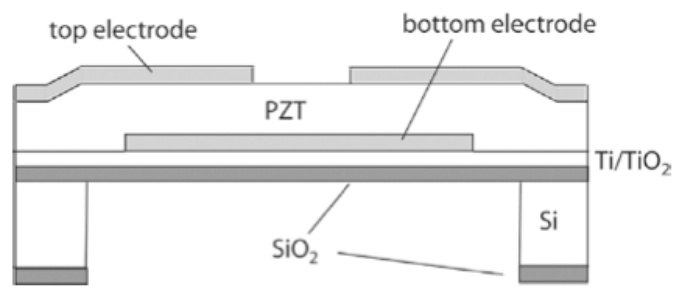

Fig. 15: Cross section of TFBAR with double resonator membrane structure [38].

\subsection{Ultra Temperature Stable $\mathrm{BAW}$ with $\mathrm{SiO}_{2}$ Compensation Layer}

A device with a very high quality factor and stable temperature characteristic is crucial for its local oscillator. A previous method of incorporating a heater in the FBAR consumes a large amount of power. A support $\mathrm{SiO}_{2}$ layer that has an opposite TCF to the piezoelectric layer is proposed for temperature compensation as shown in Fig. 16.

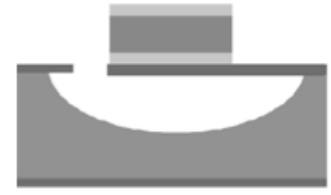

FBAR

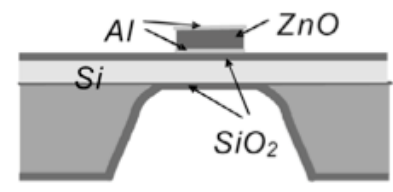

HBAR

Fig. 16: FBAR and HBAR resonator with $\mathrm{SiO} 2$ compensation layer [39].

Two configurations of a BAW were proposed: An FBAR and a high overtone acoustic resonator (HBAR) to compare the performance. FBAR consists of $\mathrm{Al} / \mathrm{ZnO} / \mathrm{Al}$ on a thin $\mathrm{SiO}_{2}$ diaphragm. The HBAR consists of $\mathrm{Al} / \mathrm{ZnO} / \mathrm{Al}$ resonator on bulk micromachined $\mathrm{SiO}_{2} / \mathrm{Si} / \mathrm{SiO}_{2}$ as shown in Fig. 16. Usage of $\mathrm{SiO}_{2}$ that has a positive TCF is proven to compensate the BAR TCF to less than $1 \mathrm{ppm} /{ }^{\circ} \mathrm{C}$ at a frequency range of $3 \mathrm{GHz}$ to $5 \mathrm{GHz}$. The measured TCF for FBAR is $-0.45 \mathrm{ppm} /{ }^{\circ} \mathrm{C}$ at $4.4 \mathrm{GHz}$ in a temperature range of $80^{\circ} \mathrm{C}$ to $105^{\circ} \mathrm{C}$ while the $\mathrm{HBAR}$ shows zero TCF at $72.5^{\circ} \mathrm{C}$ with loaded Q of 800 at $3.427 \mathrm{GHz}$ and $32.8^{\circ} \mathrm{C}$ with loaded $\mathrm{Q}$ of 540 at $4.597^{\circ}$ [39]. The highlight of this work is achieving temperature stability passively without any external component and feedback control [39]. The measured quality factor for the FBAR is 330 at $4.4 \mathrm{GHz}$ which is relatively low due to silicon residues scatters the acoustic waves. The HBAR shows higher quality factor $(Q=800)$ and lower TCF compared to FBAR. However, precise fabrication 
is needed to control the complicated thickness ratio [39]. Stable temperature compensation is achieved using $\mathrm{SiO}_{2}$ support layer although the quality factor needs to be improved. The design is CMOS compatible and useful for oscillator integration and filter application.

\subsection{Integration of $\mathrm{AIN} / \mathrm{SiO}_{2}$ to Increase Quality Factor}

A thin film bulk acoustic wave resonator (TFBAR) composed of $\mathrm{SiO}_{2}-\mathrm{AlN}_{-} \mathrm{SiO}_{2}$ sandwiched between two electrodes was designed as shown in Fig. 17 [40]. This work proposed an integration of $\mathrm{AlN}$ and passive $\mathrm{SiO}_{2}$ material that is possible in increasing the quality factor, $Q$. The quality factor, $Q$ and coupling coefficient, $k^{2}$ is derived from Eqn. (19) and Eqn. (20) respectively where $\Phi$ is the slope of phase at resonance, $f_{r}$ is the resonance, and $f_{a}$ is the anti resonance frequency [40].

$$
\begin{aligned}
& Q=\left.\frac{f_{r}}{2} \frac{\partial \phi}{\partial f}\right|_{f_{r}} \\
& k^{2}=\frac{\pi^{2}}{4} \frac{f_{a}-f_{r}}{f_{a}}
\end{aligned}
$$

Passive and high $Q$ material such as $\mathrm{SiO}_{2}$ provides a symmetric solution for the trapped acoustic wave to ensure maximum piezoelectric transduction [40]. The $\mathrm{SiO}_{2}$ thickness is varied to $0 \mathrm{~nm}, 70 \mathrm{~nm}, 310 \mathrm{~nm}$ and $770 \mathrm{~nm}$. The finding shows that increment in $\mathrm{SiO}_{2}$ thickness increases the quality factor because $\mathrm{SiO}_{2}$ is a low loss material. The device shows an intense third harmonic with $Q$ of 1450 near $3.9 \mathrm{GHz}$ compared to fundamental harmonics at $1.3 \mathrm{GHz}$ at $770 \mathrm{~nm} \mathrm{SiO}_{2}$ thickness [40]. The simulation maximum coupling coefficient of $0.70 \%$ is achieved at a third harmonic, with $400 \mathrm{~nm}$ thickness of AlN. It can be summarized that maximum $Q$ occurrs when the displacement of the wave is a maximum on the $\mathrm{SiO}_{2}$ layers. The possibility to achieve zero temperature coefficient of frequency (TCF) that leads to a high performance of TFBAR is also highlighted. Finite element simulation results show that there is a shift of TCF to positive values when $\mathrm{SiO}_{2}$ layer is deposited. A zero TCF is achieved at $\mathrm{SiO}_{2}$ thickness of $120 \mathrm{~nm}$ and $200 \mathrm{~nm}$ for the first and third harmonic respectively. The proposed design is proven to a have high quality factor and high thermal stability when $\mathrm{SiO}_{2}$ layer is deposited.

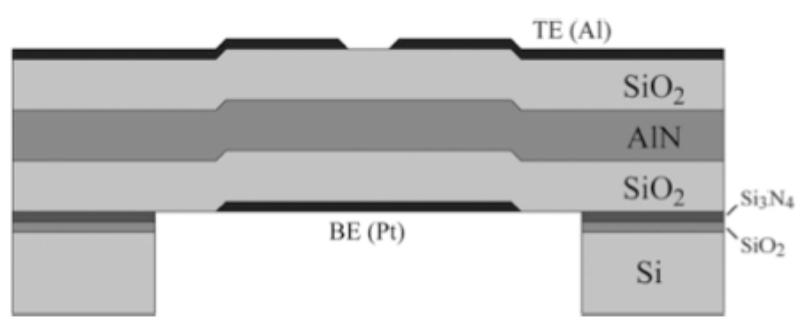

Fig. 17: FBAR and HBAR resonator with $\mathrm{SiO} 2$ compensation layer [40].

\section{PERFORMANCE EVALUATION OF SILICON COMPATIBLE ACOUSTIC WAVE RESONATORS}

SAW devices that are packaged in discrete components have been successfully used as filters, and resonators in commercial communication devices for several decades. The 
required quality factor for telecommunication industry is in the range of 10,000. This method limits the realization of single chip transceiver system. There has been motivation to design silicon compatible acoustic wave resonators to reduce the area, lower the manufacturing cost and enable multiband configurations. However, lots of efforts have been focused on achieving high quality factor, low insertion loss, and high temperature stability devices. Table 2 summarizes the current silicon compatible SAW and BAW resonators.

Table 2: Comparison table of silicon compatible acoustic wave resonators.

\begin{tabular}{|c|c|c|c|c|c|}
\hline Ref & $\begin{array}{l}\text { Acoustic } \\
\text { Configuration }\end{array}$ & $\begin{array}{l}\text { Piezoelectric } \\
\text { Material }\end{array}$ & $\begin{array}{l}\text { Resonant } \\
\text { Frequency }\end{array}$ & $\begin{array}{l}\text { Quality factor } \\
\text { (Q) Insertion } \\
\text { Loss (IL) }\end{array}$ & Fabrication method \\
\hline [30] & SAW & AlN & $5.035 \mathrm{GHz}$ & Nil & E beam Lithography \\
\hline [31] & SAW & $\mathrm{ZnO}$ & $\begin{array}{l}600 \mathrm{MHz} \text { to } \\
3540 \mathrm{MHz}\end{array}$ & $\mathrm{IL}<25 \mathrm{~dB}$ & $\begin{array}{l}\text { Conventional photolithography } \\
\text { and Wet etching }\end{array}$ \\
\hline [32] & SAW & $\begin{array}{l}\mathrm{ZnO} \\
\mathrm{AlN} \text { act as } \\
\text { protective } \\
\text { layer }\end{array}$ & $500 \mathrm{MHz}$ & IL $<30 \mathrm{~dB}$ & $\begin{array}{l}\text { RF magnetron sputtering } \\
\text { Photolithography and Wet } \\
\text { etching }\end{array}$ \\
\hline [24] & SAW & $\mathrm{ZnO}$ & $\begin{array}{l}1.02 \mathrm{GHz} \\
941 \mathrm{MHz} \text { and } \\
605 \mathrm{MHz} \text {. }\end{array}$ & $\begin{array}{l}\mathrm{Q} \text { factor is } \\
\text { between } 33 \text { to } \\
285 \\
\mathrm{IL}=35-45 \mathrm{~dB}\end{array}$ & $\begin{array}{l}\text { Post CMOS process that } \\
\text { involves reactive ion etching, } \\
\text { zinc oxide deposition and wet } \\
\text { etching }\end{array}$ \\
\hline [33] & SAW & $\begin{array}{l}\text { AlN : } \\
\text { thickness of } \\
500 \mathrm{~nm}\end{array}$ & $\begin{array}{l}\text { Mode 1: } 2.4- \\
2.5 \mathrm{GHz} \\
\text { Mode 2:3.4 } \\
\mathrm{GHz}\end{array}$ & $\begin{array}{l}10 \Omega \mathrm{cm} \mathrm{Si} \mathrm{IL=-} \\
45 \mathrm{~dB} \\
4000 \Omega \mathrm{cm} \mathrm{Si} \\
\mathrm{IL}=-60 \mathrm{~dB}\end{array}$ & $\begin{array}{l}\text { Reactive pulse DC sputtering } \\
\text { for AIN deposition } \\
\text { RIE to enable access to GSG } \\
\text { pads }\end{array}$ \\
\hline [37] & BAW (SMR) & $\mathrm{ZnO}$ & $\begin{array}{l}\text { Mode 1: } 905 \\
\text { MHz , } \\
\text { Mode 2: } 2.18 \\
\text { GHz }\end{array}$ & $\begin{array}{l}\mathrm{Q}=113 \\
\mathrm{Q}=129\end{array}$ & Not mentioned \\
\hline [38] & $\begin{array}{l}\text { BAW } \\
\text { (TFBAR) }\end{array}$ & PZT & $0.802 \mathrm{GHz}$ & $\mathrm{Q}=50$ & Sol gel technique \\
\hline [39] & $\begin{array}{l}\text { BAW(FBAR } \\
\text { and HBAR) }\end{array}$ & $\mathrm{ZnO}$ & $\begin{array}{l}\text { FBAR: } 4.4 \\
\text { GHzHBAR: } \\
3.4 \text { and } 4.6 \\
\mathrm{GHz}\end{array}$ & $\begin{array}{l}\text { FBAR: } Q=330 \\
\text { HBAR: } Q=800 \\
\text { and } 540\end{array}$ & $\begin{array}{l}\text { Bulk } \\
\text { micromachiningEvaporation } \\
\text { Vapor etching }\end{array}$ \\
\hline [40] & BAW & AlN & $\begin{array}{l}\text { Mode 1: } 1.3 \\
\text { GHzMode } 3: \\
\text { 3.9 GHz }\end{array}$ & $\begin{array}{l}\text { Q: } 1450 \text { for } \\
\text { mode } 3 .\end{array}$ & Deep silicon etching \\
\hline
\end{tabular}

For $\mathrm{GHz}$ resonator design, most of the previous works still have low quality factors of below 5000 and high insertion loss. The chosen piezoelectric material plays an essential role to achieve high electromechanical coupling coefficient for better resonator performance. $\mathrm{ZnO}$ and $\mathrm{AlN}$ thin films are the choice of piezoelectric material due to silicon compatibility for CMOS integration compared to PZT. Successful fabrication of a CMOS SAW resonator eliminates the separate deposition steps for resonator fingers although the quality factor needs to be enhanced. The insulating passive $\mathrm{SiO}_{2}$ layer acts as low loss material and aims to increase the quality factor and temperature stability of the design. Conventional lithography limits the maximum operating frequency up to the $\mathrm{GHz}$ range. Hence, e-beam lithography technique on high resistivity (100) silicon substrates 
was introduced to design a $5 \mathrm{GHz}$ resonance frequency device. SAW performance also can be improved by using high Si substrate resistivity due to reduced capacitive coupling to the substrate. Progress is still required in the miniaturization of silicon compatible acoustic wave resonators to realize single chip transceiver system. The performance of this silicon compatible acoustic resonator still needs to be improved and optimized to achieve precise resonance frequency, high electromechanical coupling coefficient, high quality factor, low insertion loss, and high temperature stability.

\section{CONCLUSION}

In conclusion, silicon compatible acoustic resonators offer a promising solution to realize monolithic integration of wireless transceivers. Such SAW and BAW resonators are versatile and suitable for many applications due to reduction in its size with high stability, excellent aging properties, low cost at high volumes, and low insertion loss. Selection of appropriate piezoelectric material is significant and critical to ensure a high electromechanical coupling coefficient is produced to reduce insertion loss. For BAW resonators, thickness of the piezoelectric material is crucial to determine the resonance frequency produced. Other significant factors for SAW device, such as periodic distance of the IDT and number of reflectors are also crucial to maximize the quality factor and minimize the insertion loss.

\section{ACKNOWLEDGEMENT}

The research was supported by the Exploratory Research Grants Scheme: ERGS 11-009009, Ministry of Education, Malaysia.

\section{REFERENCES}

[1] Quan Z. Sheng, Sherali Zeadally, Zongwei Luo, Jen-Yao Chung, Zakaria Maamar (2009) Ubiquitous RFID: Where are we?,Information Systems Frontiers, 12(5) : 485-490.

[2] Mattern F, Floerkemeier C. (2010) From the Internet of Computers to the Internet of Things, From active data management to event-based systems and more. Springer-Verlag. 2010 :242-259

[3] Wei Xie, Lei Xie, Chen Zhang, Qiang Wang, Jian Xu, Quan Zhang, Chaojing Tang, (2014)RFID seeking: Finding a lost tag rather than only detecting its missing, Journal of Network and Computer Applications, 42: 135-142.

[4] Biplob R. Ray, Jemal Abawajy, Morshed Chowdhury, (2014) Scalable RFID security framework and protocol supporting Internet of Things, Computer Networks, 67:89-103.

[5] Oita T. (2009) RF MEMS: Focusing on the next step, Ultrasonics, 2009 IEEE Symposium on: $1173-1178$.

[6] Takagi, M., Momosaki, E., Yamakita, M., Oura, Nobunori (1998) K-cut quartz SAW resonators for stable frequency sources IEEE Transactions on Ultrasonics, Ferroelectrics and Frequency Control 45(2): 328-337.

[7] El Habti, A., Bastien, F., Bigler, E., Thorvaldsson, T. (1995) Experimental study of SAW quartz resonators at very low temperature, Ultrasonics, 1995 IEEE Symposium on, 1:71-76.

[8] N Naumenko and B Abbott, (2003) Optimal orientations of lithium niobate for resonator SAW filters, Ultrasonics, 2003 IEEE Symposium on 2: 2110-2113.

[9] Kyeongdong Park, M Esashi, and S Tanaka, (2011)Lithium-niobate-based surface acoustic wave device directly integrated on IC, Ultrasonics, 2011 IEEE Symposium on: 1956-1959.

[10] Ramli NA, Nordin AN. (2011) Design and modeling of MEMS SAW resonator on Lithium niobate. International Conference of Mechatronics (ICOM-2011):1-4.

[11] Slobodnik, A.J., Jr., Silva, J.H.; Kearns, William J., Szabo, T.L. (1978) Lithium tantalate 
SAW substrate minimal diffraction cuts, IEEE Transactions on Sonics and Ultrasonics 25(2):92-97.

[12] Ruppel, C.C.W., Reindl, L., Weigel, R. (2002) SAW devices and their wireless communications applications, IEEE Microwave Magazine 3(2): 65-71.

[13] Weigel, R., Morgan, D.P., Owens, J.M., Ballato, A., Lakin, K.M., Hashimoto, Ken-Ya; Ruppel, C.C.W.(2002) Microwave acoustic materials, devices, and applications. IEEE Transactions on Microwave Theory and Techniques 50(3):738-749.

[14] Mansour RR. (2013) RF MEMS-CMOS Device Integration: An overview of the potential for RF researchers. IEEE Microwave Magazine 14(1):39-56.

[15] Varadan VK, Vinoy KJ, Jose KA. (2003) RF MEMS and Their Applications Wiley 2003: 15.

[16] Rebeiz GM. (2004) RF MEMS: theory, design, and technology.Wiley 2004:1-20.

[17] Bouchaud, J., Knoblich, B., Wicht, H. (2006) Will RF MEMS live up their promise? Microwave Conference 2006 36th European,:1076-1079

[18] Voiculescu I, Nordin AN.(2012). Acoustic Wave Based MEMS Devices, Development and Applications, Microelectromechanical Systems and Devices, Dr Nazmul Islam (Ed.), ISBN: 978-953-51-0306-6, InTech, DOI: 10.5772/28214.

[19] Campanella H.(2010) Acoustic Wave and Electromechanical Resonators: Concept to Key Applications (Integrated Microsystems). Artech House 2010:1-364.

[20] Beeby SP, Tudor MJ, White NM. (2006)Energy harvesting vibration sources for microsystems applications,Measurement Science and Technology 17(12) : R175-R195.

[21] Hashimoto K. (2000)Surface Acoustic Wave Devices in Telecommunications. Springer Verlag.

[22] Ralib AAM, Nordin AN, Salleh H.(2010)A comparative study on MEMS piezoelectric microgenerators, Microsystem Technologies 16(10):1673-1681.

[23] Campbell C. (1998) Surface Acoustic Wave Devices for Mobile and Wireless Communications. Academic Press. 1998:19-34.

[24] Nordin AN, Zaghloul ME. (2007) Modeling and Fabrication of CMOS Surface Acoustic Wave Resonators,"Microwave Theory and Techniques, IEEE Transactions on 55(5): 992_ 1001.

[25] Datta S. (1986) Surface Acoustic Wave Devices. Prentice Hall.

[26] Nordin AN. (2008)Design, Implementation and Characterization of Temperature Compensated SAW Resonators in CMOS Technology for RF Oscillators. PhD Thesis, Goerge Washington University, School of Engineering and Applied Science, ProQuest.

[27] Hashimoto K. (2009) RF Bulk Acoustic Wave Filters for Communications. Artech House. 2009:1-292.

[28] Larson, J.D., III.; Bradley, R.C.; Wartenberg, S.; Ruby, R.C. (2000)Modified ButterworthVan Dyke circuit for FBAR resonators and automated measurement system,Ultrasonics Symposium, 2000 IEEE 1: 863-868.

[29] Lin CM. (2012)Temperature Compensation of Aluminum Nitride Lamb Wave Resonators Utilizing the Lowest-Order Symmetric Mode .PhD Thesis University of California, Berkeley, EECS Department.

[30] Neculoiu D, Müller A, Deligeorgis G, Dinescu A, Stavrinidis A, Vasilache D, Cismaru AM, Stan GE, Konstantinidis G. (2009)AlN on silicon based surface acoustic wave resonators operating at $5 \mathrm{GHz}$, Electronics Letters 45(23): 1196-1197.

[31] Le Brizoual L, Sarry F, Elrnazria O, Alnot P, Ballandras S, Pastureaud T. (2008) GHz frequency $\mathrm{ZnO} / \mathrm{Si} \mathrm{SAW}$ device,IEEE Transactions on Ultrasonics, Ferroelectrics and Frequency Control 55(2) : 442-450.

[32] Legrani O, Elmazria O, Zhgoon S, Pigeat P, Bartasyte A. (2013) Packageless AlN/ZnO/Si structure for SAW devices applications. IEEE Sensors Journal 13(2):487-491.

[33] Kaletta U, Wolansky D, Fraschke M, Wenger C. (2012) Development of CMOS integrated AIN based SAW-Filter and the role of $\mathrm{Si}$ substrate resistivity, in International Semiconductor Conference Dresden-Grenoble (ISCDG) : 79-82.

[34] Clement M, Vergara L, Sangrador J, Iborra E, Sanz-Hervas A. (2004) SAW characteristics 
of AlN films sputtered on silicon substrates. IEEE Transactions on Ultrasonics, Ferroelectrics, and Frequency Control 42(1-9):403-407.

[35] Mahon S, Aigner R. (2007) Bulk acoustic wave devices-why, how, and where they are going, CS MANTECH Conference : 1-4

[36] Dubois MA (2003)Thin film bulk acoustic wave resonators: a technology overview, Memswave :1-4.

[37] Johnston ML, Kymissis I, Shepard KL. (2008) FBAR-CMOS oscillator array for masssensing applications. IEEE Sensors Journal 5(2):442-450.

[38] Conde J, Muralt P. (2008) Characterization of sol-gel $\mathrm{Pb}\left(\mathrm{Zr}_{0.53} \mathrm{Ti}_{0.47}\right) \mathrm{O}_{3}$ in thin film bulk acoustic resonators. IEEE Transactions on Ultrasonics, Ferroelectrics, and Frequency Control 55(6):1373-1379.

[39] Yu H, Pang W, Zhang H, Kim ES. (2007) Ultra temperature-stable bulk-acoustic-wave resonators with $\mathrm{SiO}_{2}$ compensation layer. IEEE Transactions on Ultrasonics, Ferroelectrics and Frequency Control 54(10):2102-2109.

[40] Artieda A, Muralt P. (2008) High-Q AlN/SiO 2 symmetric composite thin film bulk acoustic wave resonators. IEEE Transactions on,Ultrasonics, Ferroelectrics and Frequency Control, 55(11):2463-2468.

\section{BIOGRAPHIES}

Aliza Aini Md Ralib received the B. Eng (Hons) Computer and Information Engineering AND M.S. degree from the International Islamic University Malaysia (IIUM), Kuala Lumpur, Malaysia in 2006 and 2010. She is currently working towards a PhD in Electronic Engineering. Her main research interests are VLSI and MEMS. She is currently involved in the design and simulation of CMOS surface acoustic wave devices.

Assoc. Prof. Dr. Anis Nurashikin Nordin received the B. Eng. Degree in Computer and Information Engineering from the International Islamic University Malaysia (IIUM), Kuala Lumpur, Malaysia in 1999, and the M.S degree in Computer Engineering from the George Washington University (GWU), Washington DC, in 2002, and the D. Sc. Degree in Electrical and Computer Engineering at GWU. Currently, she is a lecturer at International Islamic University Malaysia (IIUM).Her main research interests are VLSI and RF MEMS, SAW Resonators, and particularly oscillators. 